\title{
A constante presença do Facebook no espaço escolar
}

The constant presence of Facebook at school

Fernanda Ribeiro Barros, Mestranda do Programa de Pós-Graduação em Mídia e Cotidiano do Instituto de Arte e Comunicação Social da Universidade Federal Fluminense, Niterói/RJ. E-mail: fernandyrb@gmail.com.

Alexandre Farbiarz, Professor do Programa de Pós-Graduação em Mídia e Cotidiano do Instituto de Arte e Comunicação Social da Universidade Federal Fluminense, Niterói/RJ. Doutor em Design pela Pontifícia Universidade Católica do Rio de Janeiro, RJ. E-mail: alexandre.farbiarz@gmail.com.

\section{Resumo}

O presente estudo visa apresentar a realidade do cotidiano de uma escola estadual de Niterói, quanto ao uso do Facebook pelos alunos através dos dispositivos móveis, considerando especialmente alguns conceitos e aspectos da comunicação como: espaço e ciberespaço, cotidiano, lugar e não lugar.

Palavras - chave: Facebook, escola pública, cotidiano.

\section{Abstract}

This study aims to present the daily activities in a state school of Niterói regarding the use of Facebook by students via mobile devices, considering some concepts and aspects of communication as space and cyberspace, quotidian, place and no place.

Keywords: Facebook, public school, quotidian. 
A comunicação móvel no Brasil vem crescendo a partir do momento em que se faz presente nas diferentes classes sociais. Através da tecnologia móvel, as conexões de rede estabelecidas têm proporcionado oportunidades e também alguns desafios nas relações interpessoais e nos espaços públicos e privados. Conforme se aprimoram as especificidades e funcionalidades destes aparelhos, mais eles começam a se tornar parecidos com computadores, possibilitando o processo de inclusão digital por serem mais baratos e pela possibilidade de conexão à rede. (PELLANDA, 2009).

Numa determinada pesquisa realizada pelo $\mathrm{IBGE}^{1}$, em 2011, foram visitados 146 mil domicílios e entrevistadas 359 mil pessoas. Deste modo, algumas constatações em relação ao acesso à Internet podem ser consideradas. No Brasil, por exemplo, o percentual de pessoas de 10 anos ou mais de idade que acessaram a Internet passou de 20,9\% (31,9 milhões) em 2005 para 46,5\% (77,7 milhões) em 2011.

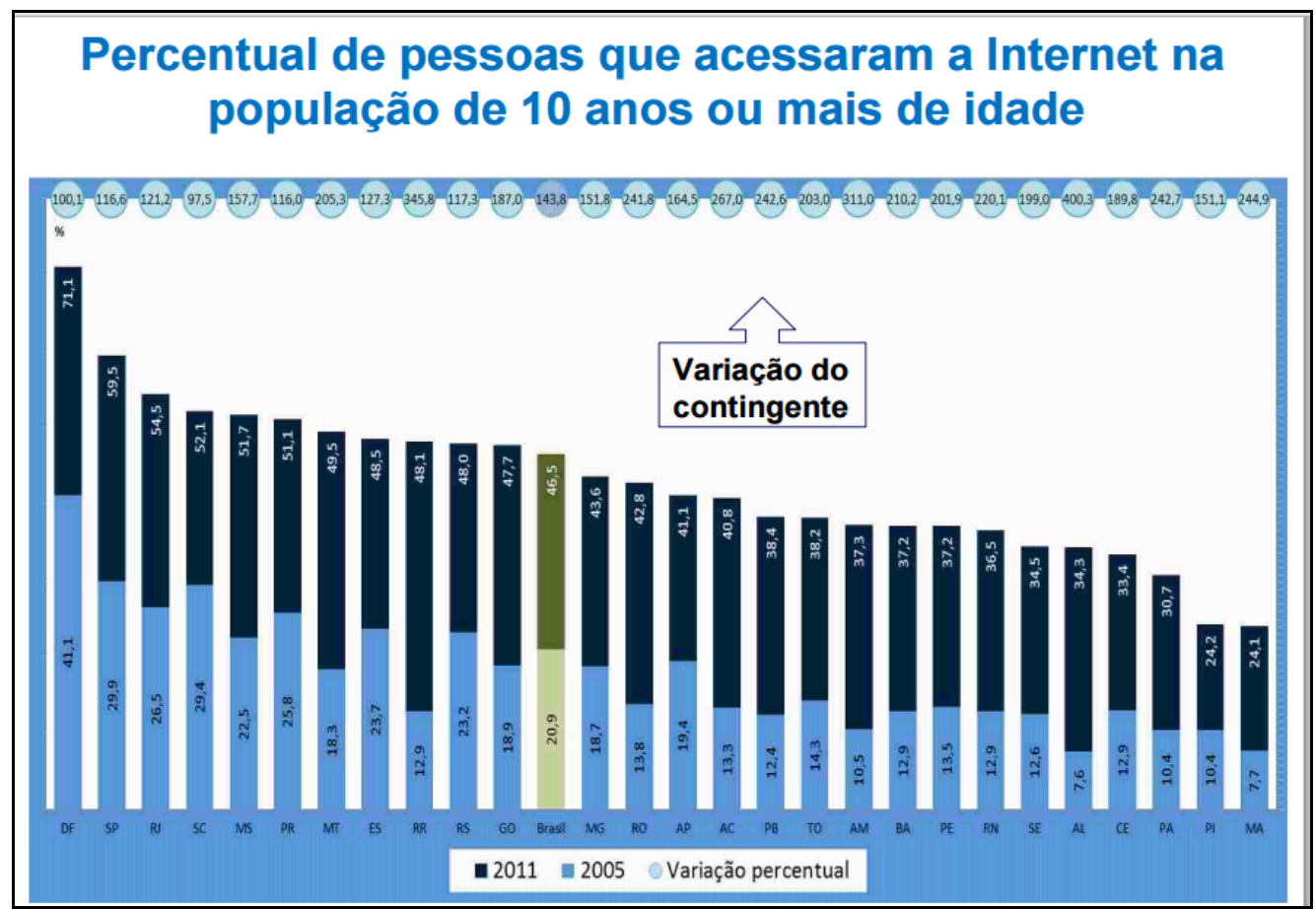

Fonte: IBGE. Pesquisa Nacional por Amostra de Domicílios. Acesso à Internet e Posse de Telefone Móvel Celular para Uso Pessoal, 2011.

$\mathrm{Na}$ classe de rendimento mensal domiciliar per capita de mais de 3 a 5 salários mínimos registrou-se o maior porcentual de Internautas.

1 IBGE: Instituto Brasileiro de Geografia e Estatística. Disponível em:<http://www.ibge.gov.br/home/estatistica/populacao/acessoainternet2011/>. Acesso: 12/07/2015. 


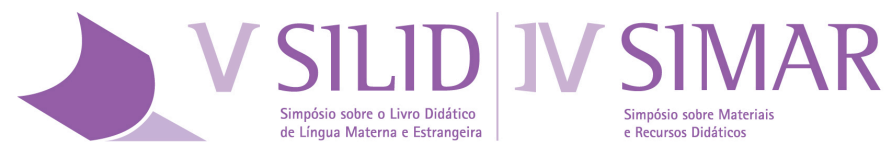

PUC-Rio - Dias 28,29 e 30 de julho de 2015

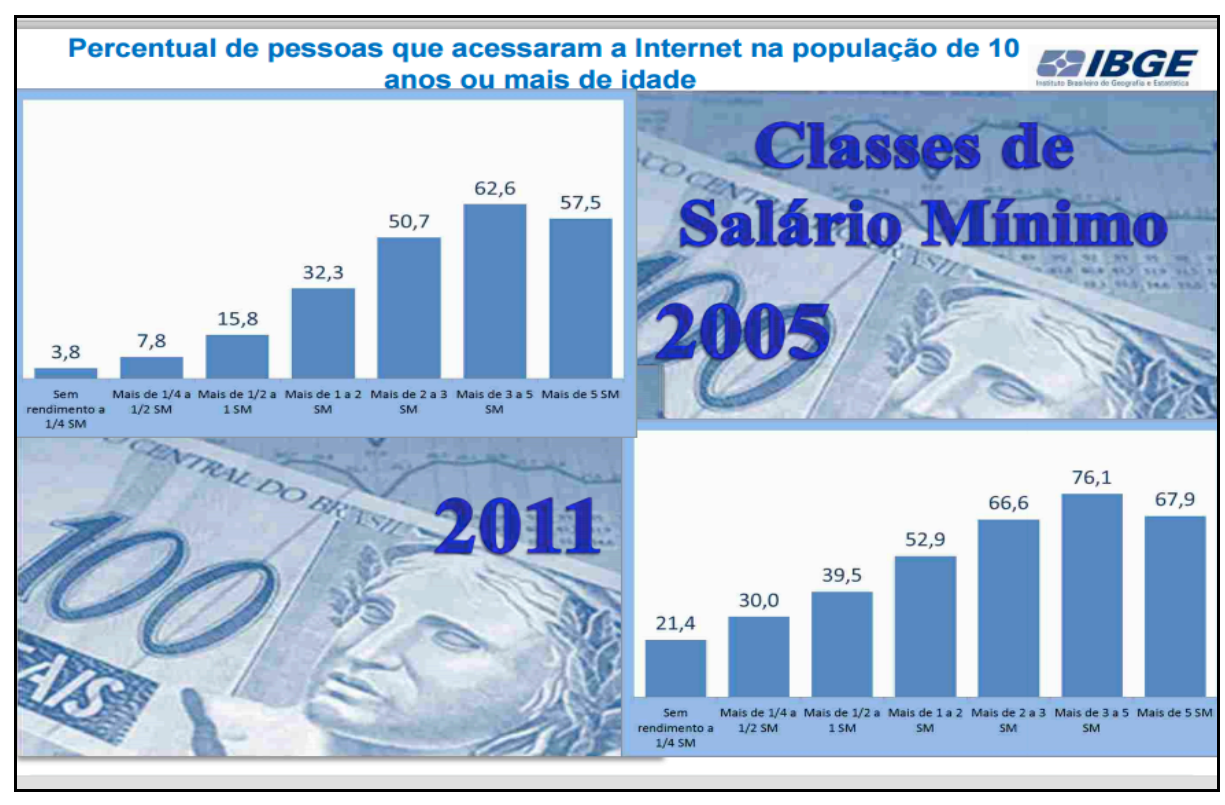

Fonte: IBGE. Pesquisa Nacional por Amostra de Domicílios. Acesso à Internet e Posse de Telefone Móvel Celular para Uso Pessoal, 2011.

Entre os jovens, o percentual de internautas era ainda maior em 2005 e assim permaneceu em constante crescente até 2011.

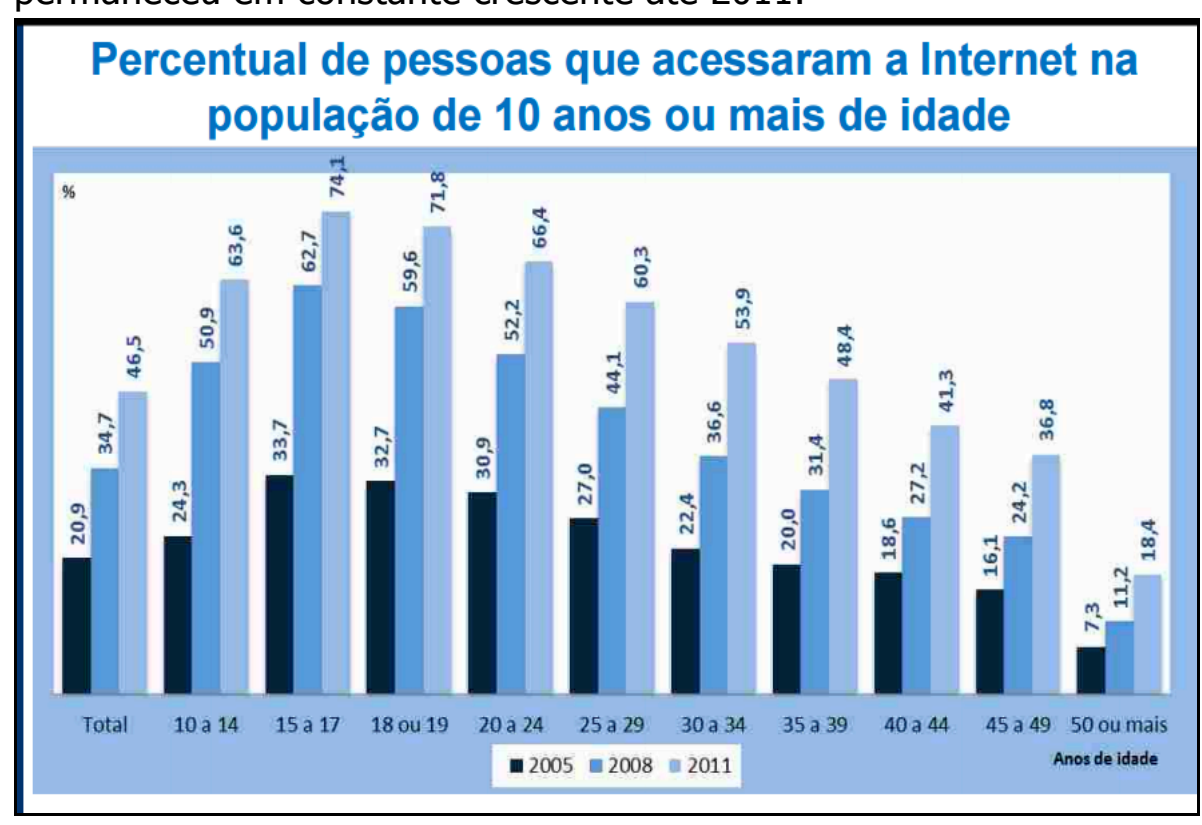

Fonte: IBGE.Pesquisa Nacional por Amostra de Domicílios. Acesso à Internet e Posse de Telefone Móvel Celular para Uso Pessoal, 2011.

O acesso à Internet chega a 90,2\% entre as pessoas com 15 anos ou mais de estudo. 


\section{SILID IV SIMAR}

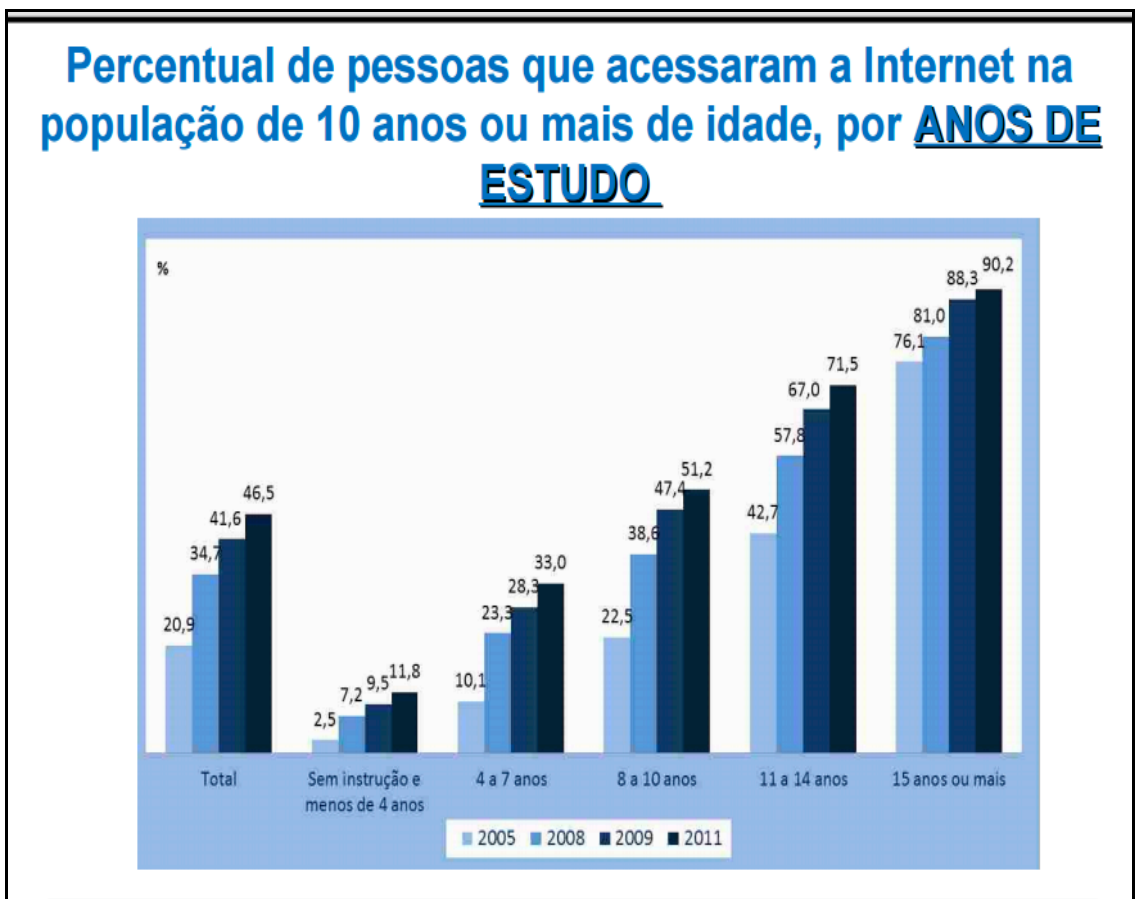

Fonte: IBGE. Pesquisa Nacional por Amostra de Domicílios. Acesso à Internet e Posse de Telefone Móvel Celular para Uso Pessoal, 2011.

$\mathrm{O}$ acesso à Internet entre os estudantes de 10 anos ou mais de idade, que estudavam em escola pública, passou de $24,1 \%$ para $65,8 \%$.

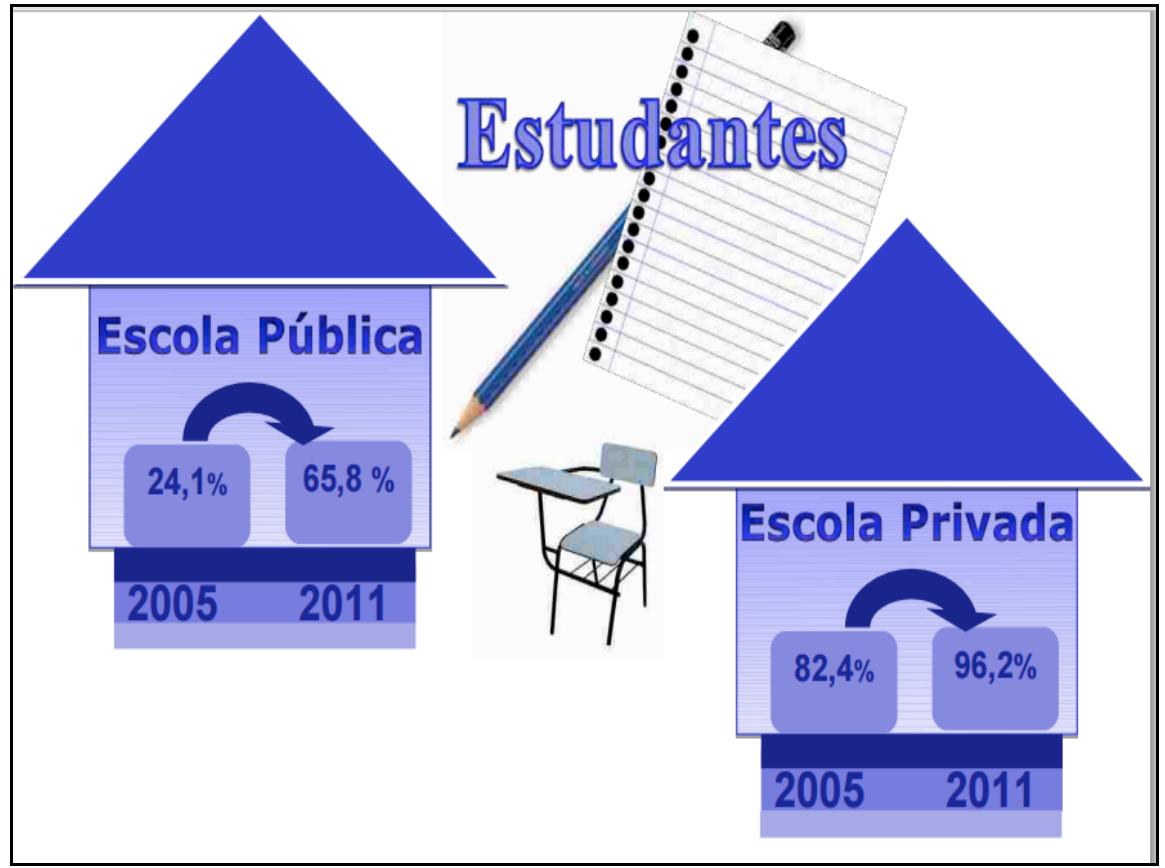

Fonte: IBGE. Pesquisa Nacional por Amostra de Domicílios. Acesso à Internet e Posse de Telefone Móvel Celular para Uso Pessoal, 2011. 
Para Pellanda, apesar de o Brasil ser um país de consideráveis diferenças sociais, com a grande maioria da população vivendo na miséria, ele é uma das nações a adotar cada vez mais as novas tecnologias e culturas digitais. Deste modo, o Brasil é líder em recolhimento de impostos provenientes do serviço de Internet. A comunicação móvel no Brasil está transformando as atividades econômicas e sociais de maneira profunda e a população também está no topo dos países que mais estão conectadas à rede, proporcionalmente ao número de internautas, além de ser a maioria em comunicação em comunidades virtuais como o Facebook ${ }^{2}$.

Um levantamento feito com 1.300 entrevistas pessoais, em 70 cidades do país, entre o final de setembro e outubro de 2012 mostra que um terço dos brasileiros acessou ao menos uma rede social nos últimos 90 dias. Futebol, religião, política, trabalho, novela, autoajuda, humor e sexo são os assuntos mais compartilhados e procurados pelos brasileiros em diversas redes sociais (Facebook, Twitter, LinkedIn, Twitter, MSN, Google Plus, Tumblr, Myspace e YouTube), conforme mostra a pesquisa "Papo Social" realizada pela agência de pesquisas Hello Research ${ }^{3}$. O Facebook, de acordo com o levantamento da Hello Research ${ }^{4}$, é a rede mais acessada por $84 \%$ dos participantes - o equivalente a 55 milhões de pessoas, especialmente nas classes sociais $\mathrm{D}$ e $\mathrm{E}$ - as classes mais populares. $\mathrm{O}$ grupo, que tem uma frequência de acesso moderada, é representado por homens, das classes B e C, com idade entre 16 e 30 anos.

Considerando as pesquisas e levantamentos apresentados, como educadora e pesquisadora, ao observar o cotidiano da Escola Estadual Doutor Memória em que trabalho, na zona norte do município de Niterói, percebi que durante os intervalos das aulas diversos grupos de alunos, que embora parecessem estar conversando ou trocando ideias, apresentavam outra realidade de convívio. Grande parte deles possuem celulares e acessam redes sociais como o Facebook para trocarem informações e compartilharem conteúdos entre os alunos da escola ou com outras pessoas na rede. Deste modo, percebe-se também a ineficácia da política de proibição ao uso de celulares no espaço escolar, como prevê na Lei No 5.222 de 14 de abril de $2008^{5}$. Com isto, as conversas estabelecidas entre estes alunos no espaço escolar, vão além deste próprio espaço e se desdobram em vários espaços não físicos, ou seja, nos ciberespaços.

Para compreender onde, os modos e com que frequência, os alunos utilizam os dispositivos móveis e acessam o Facebook e como a escola observada lida com

${ }^{2} O$ Facebook é um site e serviço de rede social disponível em https://www.facebook.com/.

${ }^{3}$ Disponível em < http://g1.globo.com/tecnologia/noticia/2012/12/um-terco-dos-brasileirose-arroz-de-festa-no-facebook-diz-estudo.html> ou <http://www.helloresearch.com.br/>. Acesso em: 17/07/2015

${ }^{4}$ Hello Research - Pesquisa de Mercado e Inteligência.

5 Disponível em <http://m.estadao.com.br/noticias/geral,lei-proibe-telefones-celulares-emsalas-de-aula-do-rj,156681,0.htm> Acesso em: 11 de janeiro de 2015. 
esta realidade, a discussão, perpassa a questão da vida cotidiana de jovens no espaço escolar, considerando suas relações interpessoais e com os dispositivos móveis, como os celulares. Propõe-se como reflexão teórica os estudos de Heller (1992) e Certeau (1994) sobre o cotidiano. Augé (1997) e Castells (1999) sobre o ciberespaço e não lugares, e Santaella (2009) em relação à mobilidade do corpo no virtual. Goffman (2013) com a discussão sobre o "eu" e as possibilidades de representações individuais no cotidiano. Bauman (2009), Lemos (2009) e Pellanda (2009) com abordagens sobre a as características da sociedade atual, principalmente sobre o Brasil. Sodré (2012) com uma reflexão importante sobre o papel da Educação na atual sociedade. E por fim, Santos e França (2012) para uma contextualização da realidade escolar e social da escola - campo de análise e observação deste estudo.

Articuladas ao levantamento bibliográfico específico para desenvolver o tema em questão e responder ao problema, serão utilizadas informações encontradas através de observações e entrevistas informais com duas professoras. A primeira entrevistada foi a professora de ciências Ana Lúcia ${ }^{6}$. Ela vem exercendo há vinte e nove anos o magistério em escola pública, porém trabalha nesta escola apenas há seis meses. A segunda entrevista foi feita com a professora de português,Maria Graziela. Ela tem quarenta e três anos de idade, vinte e quatro anos de magistério em escola pública estadual e há treze anos trabalha nesta escola estadual.

A Escola Estadual Doutor Memória teve seu prédio inaugurado em 15 de dezembro de 1996 (SANTOS; FRANÇA, 2012), atendendo crianças e adolescentes do Ensino Fundamental ao Ensino Médio, incluindo as classes de Educação de Jovens e Adultos. Atualmente 0 atendimento tem sido unicamente para 020 segmento do Ensino Fundamental diurno, que corresponde ao 60, 70, $8^{\circ}$ e 90 ano da Educação Básica.

De acordo com a Maria Graziela, os alunos da Escola Estadual Doutor Memória são em sua maioria adolescentes entre 11 e 16 anos, que moram em comunidades existentes ao redor da escola. Segundo a professora, a maioria dos alunos ingressa na escola desde o $6^{\circ}$ ano, sendo possível acompanhar o seu desenvolvimento desde então. A professora ressaltou conhecer alguns dos alunos desde os seis anos de idade, pois ingressaram no momento em que a escola ainda atendia ao $1^{\circ}$ ano do Ensino Fundamental e ali permaneceram. Maria Graziela enfatizou que a maioria dos alunos é extremamente alegre, animados e têm muita energia, até mesmo pela jovialidade. Não obstante, observa que, como todos os adolescentes, os alunos adoram desafiar, quebrar regras, confrontar e são muito sensíveis à crítica, acreditando que, pela convivência com a violência em suas comunidades, podem se tornar agressivos "num piscar de olhos".

\footnotetext{
${ }^{6}$ A professora entrevistada não informou a idade.
} 


\section{O cotidiano escolar}

Segundo Heller (1992), a vida cotidiana é a vida do homem todo. É na vida cotidiana que o homem exerce a sua particularidade e "genericidade". Deste modo, consideramos que todas as pessoas participam da vida cotidiana em todos os aspectos de sua individualidade e de sua personalidade. É na vida cotidiana que expressamos nossos sentidos, capacidades intelectuais, paixões, sentimentos, impressões, ideais e ideologias. Enquanto instituição social, a escola é parte da vida cotidiana de crianças, adultos, jovens e idosos. Na cotidianidade da escola somos sujeitos ativos e também receptivos, expomos e adquirimos conhecimentos formais e informais.

Sobre este tema, Certeau (1994) afirma que no cotidiano há uma elaboração sobre as informações que são recebidas. Recebemos informações de diversas mídias a todo instante e sobre elas fabricamos outros conhecimentos e ideias. $\mathrm{O}$ autor considera também que não se sabe ao certo o que os usuários fazem com aquilo que recebem.

Deste modo, a mídia no cotidiano da escola poderá ter o papel de estímulo à leitura, interpretação e outra diversidade de possibilidades de aprendizagem, beneficiando o processo de ensino aprendizagem. Todavia, as mídias também influenciam nas atitudes e opiniões, mesmo que não percebamos nitidamente as transformações que podem causar. Isto, de algum modo, pode também interferir no cotidiano escolar (BARROS, 2013).

\section{Do espaço escolar ao ciberespaço}

Goffman (2013) em seus estudos apresenta uma visão de cotidianidade que remete ao modo como muitas das crianças e jovens se representam em meio à vida cotidiana e, consequentemente, no cotidiano escolar. Segundo o autor, existem dois modos de expressividade do indivíduo: a que ele transmite (símbolos verbais) e a que ele emite (gama de ações) mais teatral e contextual. Portanto, o indivíduo se expressa não por uma resposta particular, mas na busca por uma aceitação ou aprovação do seu grupo ou posição social, o que se torna relevante para sua inclusão e um convívio aparentemente mais homogêneo.

Em relação a esta análise, e considerando as mídias, Lemos (2009) afirma que:

As mídias conformam a percepção do espaço e a própria subjetividade em um jogo de espelhos mostrando o nosso lugar no mundo (em relação a outros lugares no mundo), a nossa identidade (em relação a outras culturas), além de organizar o arranjo espacial da sociedade, das cidades e das instituições. [...] Podemos definir as mídias locativas como dispositivos sensores e redes digitais sem fio e seus respectivos bancos de dados "atentos" a lugares e "contextos". Dizer que essas mídias são 
atentas a lugares e a contextos significa dizer que elas reagem informacionalmente aos mesmos, sendo eles compostos por pessoas, objetos e/ou informação, fixos ou em movimento. (LEMOS, 2009, p. 90)

Neste contexto se introduz a noção de lugar e não-lugar de Augé (1997). Segundo o antropólogo a mobilidade não cria espaços, mas sim não - lugares em que se transformam lugares e suas próprias fronteiras, pois ao mesmo tempo em que são espaços reais há a relação que seus utilizadores mantêm com esses espaços. Deste modo, o uso da Internet pode estar vinculado ao lugar e não lugar concomitantemente.

Destarte, para Lemos (2009), o lugar já não é mais um problema para o acesso e as trocas de informações em rede. Segundo o autor, as mídias locativas permitem que pessoas se conheçam, compartilhem e, em um mesmo lugar, possam interagir, trocar informações e eventualmente se encontrarem.

A característica fundamental das mídias locativas é que elas alimentam, paradoxalmente, localização e mobilidade. Movimentar é sempre "deslocar", o que poderia levar rapidamente à ideia de um apagamento dos lugares. No entanto, o deslocamento (mobilidade física e informacional) não significa necessariamente, o desaparecimento da dimensão espacial em sua materialidade e suas dimensões sociais, políticas e econômicas. [...] Se a mobilidade era um problema na fase do upload do ciberespaço (ir ou sair do local de conexão), na atual fase do download (ou internet das coisas), a mobilidade é uma oportunidade para usos e apropriações do espaço para diversos fins (lazer, comerciais, políticos, policiais, artísticos). Aqui, mobilidade informacional, aliada à mobilidade física, não apaga os lugares, mas os redimensionam. (LEMOS, 2009, p. 91)

Em relação ao redimensionamento que Lemos (2009) defende, Castells (1999) também irá concordar ao considerar que no ciberespaço a mente se desdobra em vários espaços, se expande sem sair do lugar físico. É o tempo total que não consiste em um espaço físico, mas é a vida real.

Com o ciberespaço "pingando" nas coisas, não se trata mais da conexão em "pontos de presença", mas de expansão da computação ubíqua em "ambientes de conexão" em todos os lugares. Devemos definir os lugares, de agora em diante, como uma complexidade de dimensões físicas, simbólicas, econômicas, políticas, aliadas a bancos de dados eletrônicos, dispositivos e sensores sem fio, portáteis e eletrônicos, ativados a partir da localização e da movimentação do usuário. (LEMOS, 2009, p. 92) 
De acordo com Lemos (2009, p. 104) "as mídias locativas parecem criar novos sentidos dos lugares". E concordando com Lemos (2009), Santaela (2009, p.124) irá afirmar que:

Para alguns, a ambivalência do corpo entre o real e o virtual constitui-se no dilema representacional do ciberespaço cujo clímax apresenta-se nas fronteiras corporais que se borram nas experiências de realidade virtual.

Considerando as observações da Escola Estadual Doutor Memória é possível compreender a partir dos conceitos e da ideia de Pellanda (2009), de que a informação é trocada no ambiente virtual e aplicada no real. Diante dos dados coletados foi possível perceber que as conversas entre os alunos e grupos estão para além do espaço da escola. Embora o corpo físico estivesse ocupando um lugar real, muitas das vezes os assuntos e interesses estavam voltados para outro espaço, não físico - a Internet, mais especificamente o Facebook- rede social mais comum entre os alunos desta escola.

A professora Ana Lúcia (2014) acredita que o uso do celular desvia a atenção do aluno, atrapalhando o desempenho escolar, por isso não permite o uso do celular em suas aulas, e procura ser rigorosa quanto ao cumprimento da Lei de proibição do uso do celular em sala de aula. Em contrapartida, a professora Maria Graziela (2014), nas aulas de português os alunos costumam usar seus celulares, para fotografarem coisas da lousa, e também no uso livre quando permitido pela professora. A professora acredita que todos possuem celulares, pois ter um celular com acesso a Internet e aplicativos para os alunos é um modo de ter "status" entre o grupo, porém percebe que não os utilizam de modo adequado. Além de acessarem o Facebook a professora Maria Graziela (2014) percebe que eles escutam funk constantemente, jogam joguinhos violentos e também assistem vídeos pornográficos. Neste sentido, Bauman (2009) considera que a vida líquida é precária, mas que é a vida do homem da atualidade e, consequentemente, dos jovens desta escola, vivida em condições de incertezas e de consumo - emoção, descarte - sentimento. Nela o eu torna-se algo a ser montado e manipulado para causar impressões.

\section{Considerações finais}

Considerando as observações e entrevistas, a Lei de proibição do uso dos celulares nas escolas, e os conceitos apresentados é possível compreender e perceber que há uma grande necessidade da escola se atentar a este novo e atual modelo de sociabilidade. Sobre isto, Lemos (2009, p. 89) afirma que: "o atual estágio do desenvolvimento das tecnologias digitais móveis configura-se como uma nova fase da cibercultura, a da internet das coisas".

Segundo a professora, 
As escolas ainda não sabem como lidar com esta situação. Adotar ou não o celular como método, instrumento de ensino na sala de aula? Por enquanto, os alunos associam o celular à diversão e fuga das aulas. Para eles também é status mostrar que tem celular e que tem boas músicas, bons jogos, bons aplicativos instalados e que estão compartilhando. É uma das poucas aquisições e diversões deles. Eu não costumava permitir o celular em sala de aula por causa da lei de proibição, mas já estou começando a permitir que tirem fotos da matéria no quadro para arquivo pessoal e também peço que comuniquem com alunos faltosos para tratar assuntos da aula como passar data de provas, trabalho, e dar recados. Também permito que escutem música quando estiverem só copiando do quadro. Acho que já é um começo, mas ainda é muito difícil estabelecer regras de uso, pois eles querem usar a todo o momento. (GRAZIELA, 2014)

De acordo com a Proposta de Diretrizes para a Formação Inicial de Professores da Educação Básica, em cursos de nível superior (2000), uma das exigências que se destaca para o papel do docente é orientar e mediar o ensino para a aprendizagem dos alunos. Neste mesmo documento há uma preocupação em relação aos professores que não foram e não estão sendo preparados para cumprir tal exigência.

Assim, a proposta de Muniz Sodré (2012) para a escola num todo e para os professores é a de que "reinventemos a educação" em busca de uma mudança, e superação das utopias representadas, superando os paradigmas que construíram a escola ao longo da história, adequando a educação às virtualidades e não há modelos e padrões exteriores. Faz-se necessário, portanto, caminhar com estes jovens orientando-os sobre os pontos positivos e negativos do uso do celular, não só no cotidiano escolar, mas em outros ambientes, e também alertar sobre o que um aplicativo como o Facebook pode promover. Afinal, a escola está para ensinar e também orientar, e não apenas para se preocupar com os conteúdos programáticos.

\section{Referências Bibliográficas}

AUGÉ, Marc. Por uma antropologia de mundos contemporâneos. Rio de Janeiro: Bertrand Brasil, 1997.

BAUMAN, Zygmunt. Vida Líquida. 2a ed. Rio de Janeiro: Zahar, 2009.

BARROS, Fernanda. A mídia na educação. 2013. 81 f. Trabalho de conclusão de curso. (Graduação em Pedagogia). Faculdade de Educação, Universidade Federal Fluminense, Niterói, 2013. 
BRASIL, Ministério da Educação e do Desporto. Proposta de Diretrizes para a formação inicial de professores da educação básica, em cursos de nível superior. Brasília: MEC., (2000). Disponível em: <http://portal.mec.gov.br/cne/arquivos/pdf/basica.pdf>. Acesso: 01/09/2015

CASTELLS, Manuel. A sociedade em rede. São Paulo: Paz e Terra, 1999.

CERTEAU, Michel de. A invenção do cotidiano: artes do fazer. Tradução de Ephraim Ferreira Alves. Petrópolis: Vozes, 1994.

GOFFMAN, Erving. A representação do Eu na vida cotidiana. 19a ed. Petrópolis: Vozes, 2013.

GRAZIELA, Maria. Entrevista II. [Nov. 2014]. Entrevistador: Fernanda Ribeiro Barros. Niterói, 2014. 1 arquivo .mp3 (36 min.).

HELLER, Agnes. O cotidiano e a história. São Paulo: Paz e Terra, 1992.

LEMOS, André. Arte e mídia locativa no Brasil. In: LEMOS, André; JOSGRILBERG, Fabio (orgs.). Comunicação e mobilidade: aspectos socioculturais das tecnologias móveis de comunicação no Brasil. Salvador: EDUFBA, 2009.

LÚCIA, Ana. Entrevista I. [Nov. 2014]. Entrevistador: Fernanda Ribeiro Barros. Niterói, 2014. 1 arquivo .mp3 (24 min.).

PELLANDA, Eduardo Campos. Comunicação móvel no contexto brasileiro. In:_LEMOS, André; JOSGRILBERG, Fabio (orgs.). Comunicação e mobilidade: aspectos socioculturais das tecnologias móveis de comunicação no Brasil. Salvador: EDUFBA, 2009.

SANTAELLA, Lucia. Revisitando o corpo na era da mobilidade. In: LEMOS, André; JOSGRILBERG, Fabio (orgs.). Comunicação e mobilidade: aspectos socioculturais das tecnologias móveis de comunicação no Brasil. Salvador: EDUFBA, 2009.

SANTOS, Fernanda; FRANÇA, Teones. Sou memória, sou Cubango: recanto da raça negra - letramento, samba e fé. Rio de Janeiro: iVentura, 2012.

SODRÉ, Muniz. Reinventando a educação. Diversidade, descolonização e redes. Petrópolis: Vozes, 2012. 